DOI: $10.1515 /$ rpp-2015-0069

Master of Technology Degree, Assistant Professor, SHRISH BAJPAI Integral University, India Address: Kursi Road, Lucknow, Uttar Pradesh, India E-mail: shrishbajpai@gmail.com

Undergraduate Student, SUSHANT KHARE Integral University, India Address: Kursi Road, Lucknow, Uttar Pradesh, India E-mail: khareysushant@gmail.com

\title{
MECHATRONICS ENGINEERING EDUCATION IN INDIA
}

\begin{abstract}
Present paper aims to give an insight in the field of Mechatronics, specifically its standard of education in India. We have investigated this field right from its origin. We have analyzed how it expanded as a proper discipline of engineering and in which direction the development in this field is going now and, at the same time, its status of education in India and where we are in addressing the industry's need both in terms of quality and quantity of students. We have also assessed why Mechatronics is an essential branch considering its multi-disciplinary nature. The pount is that it holds blatant importance for time to come. Life's most complicated problems cannot be addressed by the knowledge of only one engineering science. In today's world we need professionals who are "good jack(s) of all trades and master(s) of one" changing the old saying. For implementing this edited saying students will need to address real-world problems, so laboratory-based learning should be even more emphasized in this branch. Consequently, we have also looked on the laboratory works that are included in these courses, considering what aspects should be covered in them. Skillsets required by students such as implementation of hardware, coding, system modeling have been also discussed. Future prospects in this discipline have also been explored. The epilogue consists in recommendations to educational institutions based on our findings.
\end{abstract}

Key words: Mechatronics Engineering Education, Mechatronics Engineer, Teaching Learning Material.

\section{INTRODUCTION}

The term of Mechatronics was coined by Japanese engineer Tetsuro Mori in 1969, who was working in Yaskawa (Kyura, Oho, 1996). Mechatronics comes from the combination of mechanics and electronics, hence the term. The definition of mechatronics continued to evolve after its name was given. One of the quoted definitions of mechatronics was presented by three Japanese engineers: Harashima, Tomizuka and Fukada in 1996 (Harshama, Tomizuka, Fukuda, 1996). In their words, mechatronics is defined as the synergistic integration of mechanical engineering, with electronics and intelligent computer control in the design and manufacturing of industrial products and processes. Mechatronics is a multidisciplinary field of engineering that rejects splitting engineering into separate disciplines. It aims to develop a systematic system framework or architecture suitable for embedded distributed computer-based control systems. There is an urging need for mechatronics in today's industry to meet the changing demands because it is necessary for both daily-life use products and 
spacecrafts. During the cold war era, mechatronics got into focus and rapid developments were made with the advancement of different machine systems including defense machinery as well as space science machinery. Mechatronics is a design philosophy, which encourages engineers to concurrently integrate conventional core industries with today's modern processing-developing industries (Godfrey, 2013).

India is the second largest country in the world in terms of population; the seventh largest country in the world in terms of total surface area; the tenth largest economy by market exchange rates and the third largest economy by Purchasing Power Parity (PPP). Indian population is approximately 1210 million having a literacy rate of $74 \%$ (2011 census) (Literates in India, Indian Government Census, 2011; Sushant, Shubham, Shrish, 2014; Sushant, Shrish, Bharati, 2015). India has one of the largest population of young generation (under 35 year age) in the world. Today, India has 29 states with seven union territories. At every two hundred kilometers in India language, architecture, customs, living style, dance, music and taste of food vary. India is a land of infinite diversity, fascination and infinite promises, mostly unrealized. After 1991, when the Indian market was opened to foreign companies, manufacturing in India started to grow rather rapidly. Indian public sector undertaking companies (PSUs, BHEL, HAL, SAIL, etc.) are also looking outside India for future markets which generate a big demand of skilled mechatronics engineers. Upcoming metro rail projects across India called "MAKE IN INDIA" will also generate a great demand for trained mechatronics engineers (Indian Government, MAKE IN INDIA, 2015).

Present paper has been divided into three parts. First, we have discussed the mechatronics engineering education in India at undergraduate, postgraduate, doctoral and post doctoral levels; then the future scope of mechatronics engineering in different industry and research organizations as well as the employment opportunities for mechatronics engineers; finally, mechatronics engineering education in India.

\section{THE AIM OF THE STUDY}

The aim of this study is to analyze the past and current status of mechatronics engineering education in India.

\section{THEORETICAL FRAMEWORK AND RESERCH METHODS}

Theoretical framework of our research consists of current data on engineering education system of India in the view of Mechatronics, Goverment efforts to develop this field and its future. Similar type of work was done by Mr. M Grimheden in 2005. In our study we used such research methods as case studies, ethnographic studies, action research and online searches. From the methodological view, the research was based on interdisciplinary and systematic approaches.

\section{RESULTS}

India has a big number of technical educational institutes offering undergraduate and postgraduate engineering degrees. Doctoral degrees are offered by many reputed institutions and postdoctoral degrees are offered by few premium institutions of the country. Undergraduate degree programs are available in forty-five major engineering disciplines. Undergraduate level course B.E./B.Tech is of four-year duration and it has eight semesters having 35 to 45 theory courses including four to five optional, open elective and interdisciplinary courses with 20-25 laboratory courses and a final year major project. Post graduation level course M.E/M.Tech is two-year consisting of four semesters comprising10-12 theory courses including 2-4 optional courses with two laboratory courses. The final semester is totally dedicated to the dissertation in a chosen area (Sajal, 1998; Sushant, Shrish, Bharati, 2015). Students have to defend their dissertation in the presence of an examiner from 
another Indian higher education institution. Students can choose optional courses which relate to their area of dissertation. Some technical institutions in India offer M.S. degrees of one-two year duration, which are more focused on research work with some industryrelated problems. Normally, M.S. degrees are open for the engineers, who took study leave from company and came to campus to work on a certain research problem. Reputed technical institutions offer doctoral degree programs. The research grant is provided by funding agencies (DST, MHRD etc). Doctoral programs generally last three years but they can be extended up to six as per need, but it depends upon the research problem. Postdoctoral research in India is offered by few premium institutions in which candidate needs to solve some industry-based research problems. Candidates having strong background on the subject take up research as per their interest. Postdoctoral programs last two years and they can be extended to three years. Institutions generally fund postdoctoral programs. Dual degree programs are also offered, for example, undergraduate degree together with postgraduate one, which are generally of five-year duration, and postgraduate degree with doctoral one, which depend upon the research topic and scope. Students have to complete all the courses for dual degree which are in their respective curriculum (Sushant, Shubham, Shrish, 2014; Sushant, Shrish, Bharati, 2015).

Admission to technical institutions for undergraduate courses is possible through JEE (Joint Entrance Examination) divided into stages - main and advanced - as well as through state level entrance examinations. Some institutes conduct their own entrance examination but more than $80 \%$ technical institutes take two admission test modes. For admission to postgraduate studies students have to write GATE (Graduate Aptitude Test in Engineering) which takes place in January and February yearly and it is totally computerbased test. Some institutes take their own admission test and interview. After short-listing the candidates with valid GATE are able to apply for course of their choice. GATE score is valid for two or three years depending upon the notification from organizing institute. Through this GATE score, candidates can apply for MHRD assistantship during their postgraduate studies. Doctoral admission is carried out by the respective department of the institute, which conducts tests (based on specialization or field chosen by candidates) followed by an interview. Doctoral students (full-time registration) are also eligible for assistantship from some funding agencoes. Postdoctoral admission is carried through interview; it is based on candidates' research proposal, their research background and academic qualification. Premier engineering institutions of India include Indian Institute of Science (IISc) at Bangalore, Indian Institute(s) of Technology (IIT) which are sixteen in number, National Institute(s) of Technology (NIT) which are thirty in number and newly established Indian Institute(s) of Information Technology (IIIT) which are four in number supported by Ministry of Human Resource Development (MHRD) and eight in number set up by MHRD, respective State Governments and industry partners. These are funded by Government. Besides these ones a new institute was established, namely, Indian Institute of Space Science and Technology, Thiruvananthapuram.

First department dedicated to Mechatronic System Engineering was founded at University of Lancaster, United Kingdom (UK) in 1986 (Allen, 2006). Asia Pacific Institute of Information Technology (APIIT), Panipat, Haryana affiliated to Kurukshetra University is the first institution in India, which offered mechatronics as an undergraduate engineering program (First Mechatronics Engineering Department in India, 2015). After that many institutions, namely, Manipal University, SRM University, Anna University, Hindustan University, UPES Dehradun, offer mechatronics in their four-year undergraduate program 
and establish a separate mechatronics department in their campus. Madras Institute of Technology, Chennai is the first technical institute that offered postgraduate degree in Mechatronics in India. Government opened a institute called "Central Mechanical Engineering Research Institute, Durgapur, West Bengal", which is dedicated to research and development in the field of mechatronics.

In India the first year in undergraduate curricula is common with the other engineering disciplines. In the second and third years disciplines are focused on material science, electric machines, measuring instruments, digital and analog electronics, computer programming, control engineering and robotics. In the final year disciplines are Production and Operations Management, Micro Electro Mechanical Systems (MEMS), Autotronics and optional subject based on students' final year project. Mechatronics is also offered as an optional discipline in the final year for the undergraduate students of mechanical, electronics, electrical, aeronautics and instrumentation engineering.

At the postgraduate level it is offered under the specializations of mechatronics, robotic and automation engineering by mechanical or mechatronics engineering departments in major technical institutions. This postgraduate program related to mechatronics is open for the students having undergraduate engineering degree in computer science, electronics and communication, electrical, aeronautics, mechanical and mechatronics engineering. Theoretical topics studied under it include sensors technology, robot dynamics and analysis, control systems, microcontroller, industrial robotics, fuzzy logic and neural networks, industrial hydraulics and industrial pneumatics etc. Besides these, students can choose some optional courses from mathematical, mechanical and electronics department that are useful in their final semester dissertation which includes abstract algebra, topology, numerical techniques, digital signal processing, power electronics, fluid mechanics, material science etc. At doctoral level students are to do theoretical or practical analysis for their theses (Acar, Parkin, 1996). Doctoral level research in mechatronics engineering is conducted in all standard areas in which major areas are autonomous mobile robotics, medical robotics, bio-inspired robotics, bioinstrumentation, robotic sensor, thermo fluids, mechanical vibrations, control systems, automobile etc. Few research projects funded by funding agency, government research bodies or private companies may form a part in their research work. Postdoctoral research is more focused on the industry-based problem. Volkswagen India, a German automobile company, opened its own Volkswagen Academy in Chakan, Pune and started Mechatronics Apprentices to train engineers according to their own needs (Zigwheels Report, 2014). Such types of programs are also offered by other private companies in India. Few polytechnics offer diploma in mechatronics which includes basics of diploma engineering with specialization in microcontroller, control theory, machine tool design, programmable logic controller (PLC) etc. Diploma holders will be able to apply these skills to the needs of any automated industry.

Solidworks, MATLAB, NI Labview, Scilab, AutoCAD, LibreCAD, FreeCAD, Mathematica, Open Vehicle Sketch Pad are the computer simulation softwares which are used in the labs for designing and solving complex mathematical equations for undergraduate and postgraduate students. GNU Octave, Maxima, Freemat are open source tools useful for solving mathematical computational problems of mechatronics engineering. Besides these tools, mechatronics experiments are also performed on PLC in automation labs. Rapid developments in the field of communication have improved quality of different online services. Availability and capabilities of these new communication facilities with the development of different open source web technologies enable students to conduct the experiments in web-based virtual or remote labs without going in the traditional labs 
(Moudgalya, Arora, 2010; National Programme on Technology Enhanced Learning, 2015). Physical distances, lack of resources (instrument or machine) and unavailability of experienced lab instructor with good faculty makes it difficult to conduct experiments, especially when they involve sophisticated and costly instruments. These web-based experiments fill the vacuum of the lab facilities because these are designed for remote operation, helping students to learn. This helps them in learning basic and advanced concepts through remote experiments. This is very convenient for the mechatronics engineering education community to establish a common approach to design, describe, implement and link each of the parts that compose a web-based laboratory which is useful for everyone. Ministry of Human Resource Development (MHRD) in India is developing dedicated online labs for many engineering fields in association with the Indian Institute Technology and other Indian technical institutions (National Programme on Technology Enhanced Learning, 2015; Virtual Labs, 2015). They have developed two labs named Virtual Remote Robotics and Mechatronics Laboratory (Labs, 2015). Many books are written by Indian authors which serve as textbooks in subjects related to mechatronics engineering at undergraduate and postgraduate engineering education. G. Hegde, N. Mahalik, K. Ramachandran and G. Vijayaraghavan are major Indian authors whose books are adopted as textbooks at many universities across India for different mechatronics engineering courses at undergraduate and postgraduate levels. Some online courses have also been introduced under The National Programme on Technology Enhanced Learning (NPTEL) which cover prefatory aspects of the field but they are categorized within Mechanical/Electronics section of courses (Krishnan, 2009; National Programme on Technology Enhanced Learning, 2015).

An effort is put in this direction by IIT-Kanpur, founding Center for Mechatronics for enthusiasts and researchers to support their ideas and providing them with a platform to develop. Such efforts should be appreciated. The objectives of this center are to provide proper equipments, train them and become a source of information dissemination for students.

The first refereed journal focused on Mechatronics was IEEE/ASME Transactions on Mechatronics published in the United States. There are few journals published by Elsevier and Springer on mechatronics engineering. Presently many national and international platforms are being set to put this area in spotlight.

According to Professor J. Billingsley what defines a mechatronics engineer is his/her ability to put together a concept in which strategy, computing hardware, sensors, electronics and motors are blended together in harmony, not as an improvised assembly of diverse technologies (Billingsley, 2006), that means taking the necessary parts from all diverse branches and forging them into one, thus, creating opportunities from diverse range of industries.

There are a number of choices for future mechatronics engineers to choose a career path on such as Automation Product Developer, Industrial Automation Engineer, Automation Design Engineer, Control Systems Engineer. Various Public Sector Undertakings also list vacancies for graduates in Mechatronics background for applications in the field of avionics, space technology, weapon systems etc. Some of these are Indian Space Research Organization (ISRO), Defense Research and Development Organization (DRDO), Bharat Heavy Electricals Limited (BHEL), Steel Authority of India Limited (SAIL). These organizations appoint them as Research Analysts/Scientists. The skill sets attained by individuals pursuing Mechatronics engineering are highly in demand from industries all over the world because such trained individuals can take care of manufacturing process. Industries that invite applications from graduates in this subject are Consumer Electronics, Medical Equipments, Automated Production Systems, Robotics, Automobile, Food Processing, Petrochemicals. 
Many would say that all these industries already intake students from respective Electronics, Mechanical or Electrical Engineering graduate but what sets apart a mechatronics graduate is the fact that he/she does not only know some specific sensory/machinery functions, he/she knows from the core what drives a machinery which is very efficient while troubleshooting or tackling a real-world problem. Another important aspect about this discipline is its nature of exploration as we are still in an early stage regarding its education and research in India. There are a number of challenges both in rural and urban India which could be addressed efficiently by professionals trained in this field, whether it is the expansion of Metro-Railways to Tier-II cities of India, availability of cheaper medical equipments in rural areas or development of automated solutions for different industries (Mahfooz, Al-Motairi, Ahmad, Khan, 2013). Under the Eleventh Five Year Plan, Government of India has stressed on the commencement of specialized courses on Mechatronics Engineering in IITs/IIMs and other private and national universities, as India will need 6.25 million technical and managerial personnels to scale its turn-over of automobiles and autocomponents industry to US \$ 145 Billion by 2015-2016 (Planning Commission, 2008).

\section{CONCLUSIONS}

We were surprised to know that there is no dedicated department for Mechatronics Engineering at any IIT or NIT. Even undergraduate courses for this discipline are not yet available at IITs while many other departments of private institutions of national importance do offer it as an UG course understanding the demand of tomorrow. Although there are some PG courses available at some IITs specializing in Mechatronics such as at IIT-Patna. Still the total number of seats available for this field is much less considering the need and demand of India. An interesting fact is that even less courses are available at diploma level of this discipline. India is on a speed-way to development. With government focusing on developing infrastructure of country by launching targeted plans for industrial development, demand for trained professionals of mechatronics can easily be assessed as manufacturing today is synonymous with automated production. Whether its complicated biomedical equipments or simple toys, every bit of products today's is made by a machine to ensure quality. For handling such machines skilled professionals will be required.

We will have to understand that today's real-world problems need a inter-disciplinary approach. An engineer with conventional knowledge of one discipline will need more resources and help from other discipline's expert while a Mechatronics engineer can run along the pace of development at which human race is going. Efforts should be made to establish specialized institutes for Mechatronics as there were established for Information Technology, understanding its need at that time. It will not only highlight the importance of this field but also ensure the quality of graduates and address industry demand.

\section{REFERENCES}

1. Acar, M., Parkin, M. (1996). Engineering Education for Mechatronics. IEEE Transactions on Industrial Electronics, Volume 43, No 1, pp. 106-112.

2. Allen, G. (2006). Mechatronics Engineering: A Critical Need for This Interdisciplinary Approach to Engineering Education. In : Proceedings of the IJME-INTERTECH Conference on Synergistic Integration of Mechanical Engineering with Electronics (2006), pp. 1-21.

3. Billingsley, J. (2006). Essentials of Mechatronics. UK. : Wiley-Blackwell, 264 p.

4. First Mechatronics Engineering Department in India. (2015). Retrieved 08.09.2015 from : http://www.apiit.edu.in/mechatronics-engineering.html. 
5. Godfrey, O. (2013). Mechatronics, Principle \& Applications. Oxford : ButterworthHeinemann, $672 \mathrm{p}$.

6. Harshama, F., Tomizuka, M., Fukuda, T. (1996). Mechatronics. What is It, Why, and How? Transactions on Mechatronics, Volume 1, No 1, pp. 1-4.

7. Indian Government, Make in India. (2015). Retrieved 08.09.2015 from : http://www.makeinindia.com/.

8. IIT Patna, Mechatronics PG Curriculum at IIT-Patna. (2015). Retrieved 08.09.2015 from : http:/www.iitp.ac.in/index.php/academics/programmes/mtech-postgraduate/coursecurriculum/513-mectronics-curriculum.html.

9. Krishnan, M. (2009). NPTEL: A Programme for Free Online and Open Engineering and Science Education. In : Proceedings of the In Technology for Education, India (4-6 Aug. 2009). Technology for Education, 2009. T4E '09. International Workshop, 5 p.

10. Kyura, N., Oho, H. (1996). Mechatronics - an Industrial Perspective. IEEE/ASME Transactions on Mechatronics, Volume 1, No 1, pp. 10-15.

11. Literates in India, Indian Government Census. (2011). Retrieved 08.09.2015 from : http://censusindia.gov.in/2011 prov results/data_files $/ \mathrm{mp} / 04$ population.pdf $\% 2050 \%$ 20No23.4.pdf.

12. Mahfooz, Y., Al-Motairi, M., Ahmad, F., Khan, A. (2013). A Study of the Service Quality Issues of Internet Banking in Non-Metro Cities of India. Journal of Advanced Management Science, Volume 1, No 1, pp. 75-79.

13. Moudgalya, K., Arora, I. (2010). A Virtual Laboratory for Distance Education. In : Proceedings of the In Technology for Education (T4E (2010), pp. 190-193.

14. National Programme on Technology Enhanced Learning (NPTEL). (2015). Course: Mechatronics and Manufacturing Automation, NPTEL phase-II. Retrieved 08.09.2015 from : http://nptel.ac.in/courses/112103174/.

15. Planning Commission. (2008). Eleventh Five Year Plan (2007-2012). Retrieved 08.09.2015 from : http://planningcommission.nic.in/plans/planrel/fiveyr/11th/11_v2/11th_v ol2.pdf.

16. Sajal, P. (1998). The Development of Engineering and Technical Education in India. Global Journal of Engineering Education, Volume 2, No 3, pp. 317-326.

17. Sushant, K., Shubham, Ch., Shrish, B. (2014). Control Engineering Education in India. In : Proceedings of the 3rd IEEE International Conference on Power, Control and Embedded Systems (ICPCES - 2014). India : M.N.N.I.T., Allahabad, 4 p.

18. Sushant, K., Shrish, B., Bharati, P. (2015). Production Engineering Education in India. Management and Production Engineering Review, Volume 6, No 1, pp. 21-25.

19. Total Population of India in 2014. (2014). Retrieved 08.09.2015 from : http://www.indiaonlinepages.com.

20. Virtual Labs, Homepage. (2015). Retrieved 08.09.2015 from : http://vlab.co.in.

21. Virtual Labs, Virtual Remote Robotics and Mechatronics Laboratory. (2015). Retrieved 08.09.2015 from : http://iitkgp.vlab.co.in/?sub=40\&brch=292.

22. Virtual Labs, Mechatronics laboratory. (2015). Retrieved 08.09.2015 from : http://iitkgp.vlab.co.in/?sub=40\&brch=242

23. Zigwheels Report. (2014). First Volkswagen India Mechatronics Programme Concludes. Retrieved 08.09.2015 from : http:// www.zigwheels.com/newsfeatures/news/firs $\mathrm{t}$ volkswagen india mechatronics programme concludes $/ 19989 / \mathrm{m} / 513$-mectronics-curriculum. html. 